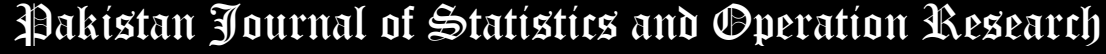

\section{The Three-parameters Marshall-Olkin Generalized Weibull Model with Properties and Different Applications to Real Data Sets}

\author{
Mohamed G. Khalil ${ }^{1 *}$ and Wagdy M. Kamel ${ }^{2}$
}

* Corresponding Author

${ }^{1}$ Department of Statistics, Mathematics and Insurance, Benha University, Benha, Egypt. hndaoy@gmail.com ${ }^{2}$ Department of Statistics, Mathematics and Insurance, Tanta University, Tanta, Egypt.

wagdykame180@yahoo.com

\begin{abstract}
A new three-parameter life parametric model called the Marshall-Olkin generalized Weibull is defined and studied. Relevant properties are mathematically derived and analyzed. The new density exhibits various important symmetric and asymmetric shapes with different useful kurtosis. The new failure rate can be "constant", "upside down-constant (reversed U-HRF-constant)", "increasing then constant", "monotonically increasing", "J-HRF" and "monotonically decreasing". The method of maximum likelihood is employed to estimate the unknown parameters. A graphical simulation is performed to assess the performance of the maximum likelihood estimation. We checked and proved empirically the importance, applicability and flexibility of the new Weibull model in modeling various symmetric and asymmetric types of data. The new distribution has a high ability to model different symmetric and asymmetric types of data.
\end{abstract}

Key Words: Marshall-Olkin Family, Weibull distribution, Order Statistics, Maximum Likelihood Estimation, Quantile function, Generating Function, Moments.

Mathematical Subject Classification: 62N01; 62N02; 62E10.

\section{Introduction}

Consider a baseline reliability function (RF) of the Weibull (W) distribution (Weibull (1951))

with probability density function (PDF)

$$
\bar{G}_{\zeta_{1}}(w)=1-G_{\zeta_{1}}(w)=\exp \left(-w^{\zeta_{1}}\right),
$$

$$
g_{\zeta_{1}}(w)=\zeta_{1} w^{\zeta_{1}-1} \exp \left(-w^{\zeta_{1}}\right)
$$

with shape parameter $\zeta_{1}>0$. The RF of the Marshall-Olkin Generalized-G (MOG-G) family of distributions is defined by

$$
\bar{F}_{\delta, \zeta_{2}, \psi}(w)=1-F_{\delta, \zeta_{2}, \psi}(w)=1-\left.\left\{\left[1-\bar{G}_{\psi}(w)^{\zeta_{2}}\right] /\left[1-\dot{\delta} \bar{G}_{\psi}(w)^{\zeta_{2}}\right]\right\}\right|_{w \in \Re, \delta>0},
$$

where $\delta$ and $\zeta_{2}$ are two positive shape parameters. The corresponding PDF of (3) is given by

$$
f_{\delta, \zeta_{2}, \psi}(w)=\left.\delta \zeta_{2} g_{\psi}(w) \bar{G}_{\psi}(w)^{\zeta_{2}-1}\left[1-\dot{\delta} \bar{G}_{\psi}(w)^{\zeta_{2}}\right]^{-2}\right|_{w \in \Re, \delta>0} .
$$

In this paper, we propose and study a new generated Weibull model called the Marshall-Olkin generalized Weibull (MOGW) distribution and give a comprehensive description of its mathematical properties. In fact, the MOGW model is motivated by its importance flexibility in application. By means of two applications, it is noted that the MOGW model provides better fits than other models each having the same number of parameters.

2. The new model and its justification

By inserting (1) in (3), we obtain the cumulative distribution function (CDF) of the MOG-G family 


$$
F_{\delta, \zeta_{1}, \zeta_{2}}(w)=\left.\frac{1-\exp \left(-\zeta_{2} w^{\zeta_{1}}\right)}{1-\dot{\delta} \exp \left(-\zeta_{2}{ }^{\zeta_{1}}\right)}\right|_{w>0, \delta, \zeta_{1}, \zeta_{2}>0},
$$

where $\delta$ and $\zeta_{2}$ are two positive shape parameters representing the different patterns of the MOGW distribution. The corresponding PDF of (5) is given by

$$
f_{\delta, \zeta_{1}, \zeta_{2}}(w)=\left.\frac{\delta \zeta_{2} \zeta_{1} w^{\zeta_{1}-1} \exp \left(-\zeta_{2} w \zeta_{1}\right)}{\left[1-\dot{\delta} \exp \left(-\zeta_{2} w \zeta_{1}\right)\right]^{2}}\right|_{w>0, \delta, \zeta_{1}, \zeta_{2}>0}
$$

Henceforth, $W \sim \operatorname{MOGW}\left(\delta, \zeta_{1}, \zeta_{2}\right)$ denotes a random variable having density function (6). The MOGW distribution is motivated by the following motivations. Suppose a system is made up of $Z$ independent components in series, where $Z$ is a random variable with geometric distribution and probability mass function

$$
\operatorname{Pr}(Z=z)=\delta \dot{\delta}^{z-1}, z=1,2, \ldots \text { and } \delta \in(0,1) \text {. }
$$

Suppose that random variables $w_{1}, w_{2}, \ldots$, represent the lifetimes of each component and suppose that they have the generalized $\mathrm{W}$ distribution. Then a random variable

$$
Y=\min \left(w_{1}, w_{2}, \ldots, w_{Z}\right)
$$

represents the time to the first failure with CDF (5).Form another view, consider now a parallel system with $Z$ independent components and suppose that a random variable $Z$ has geometric distribution with the probability mass function

$$
P(Z=z)=\delta^{-1} \dot{\delta}^{z-1}, z=1,2, \ldots \text { and } \delta>1 .
$$

Let $w_{1}, w_{2}, \ldots$ as before representing the lifetimes of each component and suppose that they have the generalized $\mathrm{W}$ distribution. Then a random variable

$$
T=\max \left(w_{1}, w_{2}, \ldots, w_{Z}\right)
$$

represents the lifetime of the system. Therefore, the random variable $T$ follows (5). The reliability function (rf), hazard rate function (HRF) and cumulative hazard rate function (cHRF) of $w$ are, respectively, given by $R(w)=$ $\frac{\delta \exp \left(-\zeta_{2} w^{\zeta_{1}}\right)}{1-\dot{\delta} \exp \left(-\zeta_{2} w^{\left.\zeta_{1}\right)}\right.}, \tau(w)=\frac{\zeta_{2} \zeta_{1} w^{\zeta_{1}-1}}{\left[1-\dot{\delta} \exp \left(-\zeta_{2} w^{\zeta_{1}}\right)\right]}$, and $H(w)=\log \left[\frac{1-\dot{\delta} \exp \left(-\zeta_{2} w^{\zeta_{1}}\right)}{\delta \exp \left(-\zeta_{2} w^{\zeta_{1}}\right)}\right]$. The MOGW distribution includes the generalized Weibull (GW) distribution when $\delta=1$. For $\zeta_{2}=1$, we obtain the MO Weibull (MOW) model. For $\zeta_{1}=1$, we have the MOG-exponential (MOGE) distribution. For $\zeta_{1}=2$, we obtain the MOG-Rayleigh (MOGR) distribution. Figure 1 gives some plots of the MOGW PDF (left) and HRF (right). From Figure 1 (left) we conclude that the PDF MOGW distribution have various symmetric and asymmetric shapes with different kurtosis. From Figure 1 (right) we note that the HRF MOGW model can be "constant", "upside down-constant (reversed U-HRF)", "increasing then constant", "monotonically increasing", "J-HRF" and "monotonically decreasing".
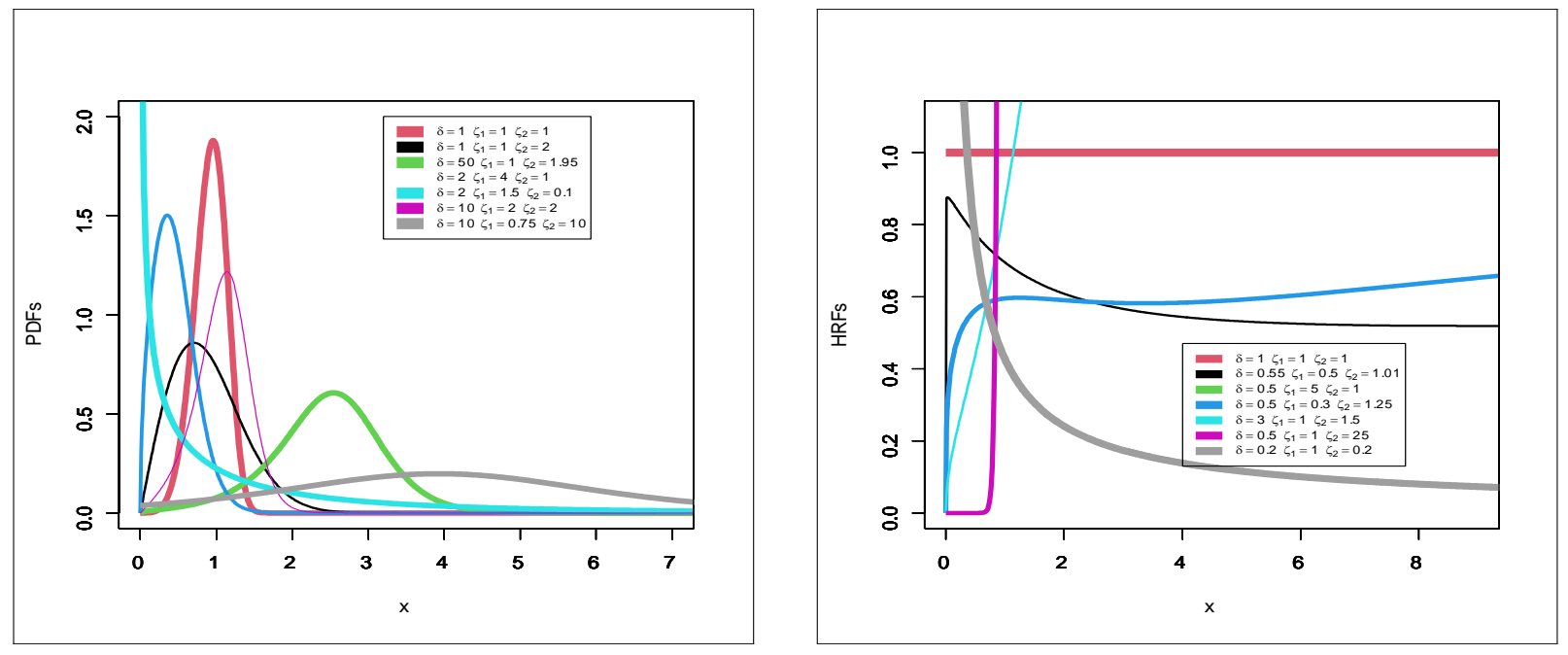

Figure 1: Plots of the MOGW PDF (left) and plots of the MOGW HRF (right) 
The main justification for the practicality of the new lifetime model is based on the wider use of the Weibull model. We are also motivated to introduce the new model since it exhibits increasing, decreasing and bathtub hazard rates. The new model can be viewed as a mixture of the exponentiated $\mathrm{W}$ distribution. It can also be considered as a suitable model for fitting the symmetric, left skewed, right skewed, and unimodal data. We prove empirically the importance and flexibility of the new model in modeling two types of lifetime data, the new model provides adequate fits as compared to other Weibull models with small values for Cramér-von Mises $\left(C_{(\text {statistic })}\right)$ and the Anderson-Darling $\left(A_{\text {(statistic) }}\right)$ and it is much better than the Odd Lindley Exponentiated Weibull, Poisson Topp Leone Weibull, the Burr X Exponentiated Weibull, Marshall Olkin extended Weibull, Gamma Weibull, Weibull-Fréchet, Kumaraswamy Weibull, Transmuted modified Weibull, Beta Weibull, McDonald Weibull, Kumaraswamy transmuted Weibull, transmuted exponentiated generalized Weibull and Modified beta Weibull models so the new good is a good alternative to these models for modeling the aircraft windshield data, as well as the new model is much better than Weibull, Modified beta Weibull, Transmuted modified Weibull, transmuted additive Weibull, exponentiated transmuted generalized Rayleigh models for modeling cancer patients data. We also conclude that the proposed model is much better than the Odd Lindley exponentiated Weibull, gamma exponentiated-exponential, odd Weibull Weibull models, and a good alternative to these models in modeling survival times of Guinea pigs. Finally, the proposed model is much better than the Odd Lindley exponentiated Weibull, exponentiated Weibull, transmuted Weibull, odd Log Logistic Weibull models, and a good alternative to these models in modeling glass fibers data.

\section{Mathematical properties}

\subsection{Linear representation}

First, we have

$$
1-\left[\exp \left(-w^{\zeta_{1}}\right)\right]^{\zeta_{2}}=1+\sum_{\kappa=0}^{\infty}(-1)^{\dot{\kappa}}\left(\begin{array}{c}
\zeta_{2} \\
\kappa
\end{array}\right)\left[\exp \left(-w^{\zeta_{1}}\right)\right]^{\kappa}=\left.\sum_{\kappa=0}^{\infty}\left[\zeta_{1}\right]_{\kappa}\left[\exp \left(-w^{\zeta_{1}}\right)\right]^{\kappa}\right|_{\dot{\kappa}=\kappa+1},
$$

where $\left[\zeta_{1}\right]_{0}=2$ and $\left[\zeta_{1}\right]_{\kappa}=(-1)^{\dot{\kappa}}\left(\begin{array}{c}\zeta_{2} \\ \kappa\end{array}\right) \forall \kappa \geq 1$ and

$$
1-\dot{\delta}-\left[\exp \left(-w^{\zeta_{1}}\right)\right]^{\zeta_{2}}=1-\dot{\delta}-\sum_{\kappa=0}^{\infty}(-1)^{\kappa}\left(\begin{array}{c}
\zeta_{2} \\
\kappa
\end{array}\right)\left[\exp \left(-w^{\zeta_{1}}\right)\right]^{\kappa}=\sum_{\kappa=0}^{\infty} \eta_{\kappa}\left[\exp \left(-w^{\zeta_{1}}\right)\right]^{\kappa},
$$

where $\eta_{0}=\delta$ and $\eta_{\kappa}=\dot{\delta}(-1)^{\dot{\kappa}}\left(\begin{array}{c}\zeta_{2} \\ \kappa\end{array}\right)$ using (7) and (8) the CDF of the MOGW model in (5) can be expressed as

$$
F_{\delta, \zeta_{1}, \zeta_{2}}(w)=\sum_{\kappa=0}^{\infty}\left[\zeta_{1}\right]_{\kappa}\left[\exp \left(-w^{\zeta_{1}}\right)\right]^{\kappa} \div \sum_{\kappa=0}^{\infty} \eta_{\kappa}\left[\exp \left(-w^{\zeta_{1}}\right)\right]^{\kappa}=\sum_{\kappa=0}^{\infty} t_{\kappa}\left[\exp \left(-w^{\zeta_{1}}\right)\right]^{\kappa},
$$

where $t_{0}=\frac{\left[\zeta_{1}\right]_{0}}{\eta_{0}}$, and for $\kappa \geq 1$ we have $t_{\kappa}=\frac{1}{\eta_{0}}\left(\zeta_{1 \kappa}-\frac{1}{\eta_{0}} \sum_{r=1}^{\kappa} \eta_{r} t_{\kappa-r}\right)$, the PDF of the MOGW model can also be expressed as a mixture of expW densities. By differentiating $F_{\delta, \zeta_{1}, \zeta_{2}}(w)$, we obtain the same mixture representation

$$
f_{\delta, \zeta_{1}, \zeta_{2}}(w)=\left.\sum_{\kappa=0}^{\infty} t_{\dot{\kappa}} \pi_{\dot{\kappa}}(w)\right|_{\dot{\kappa}=\kappa+1}
$$

where $\pi_{\omega}(w)$ is the exp W PDF with power parameter $(\omega)$. Equation (9) reveals that the MOGW PDF is a linear combination of exp W PDFs. Thus, some structural properties of the new family such as the ordinary and incomplete moments and generating function can be immediately obtained from well-established properties of the exp W distributions.

3.2 Moments and generating function

The $r^{t h}$ ordinary moment of $W$ is given by $\mu_{r}^{\prime}=E\left(w^{r}\right)=\int_{-\infty}^{\infty} w^{r} f_{\delta, \zeta_{1}, \zeta_{2}}(w) d w$, then we obtain

$$
\mu_{r}^{\prime}=\left.\Gamma\left(\frac{r}{\zeta_{1}}+1\right) \sum_{\kappa, h=0}^{\infty} \nabla_{\kappa, h}^{(i, r)}\right|_{r>-\zeta_{1}}
$$

where $\nabla_{\kappa, h}^{(\dot{\kappa}, r)}=t_{\dot{\kappa}} \nabla_{h}^{(\dot{\kappa}, r)}$ and $\nabla_{m}^{(\dot{\kappa}, \tau)}=\frac{(\dot{\kappa})(-1)^{m}\left(\begin{array}{c}\kappa \\ m\end{array}\right)}{(m+1)^{\left(\frac{\tau}{\zeta_{1}}+1\right)}}$, setting $r=1,2,3,4$ in (10) we get

$$
E(w)=\mu_{1}^{\prime}=\left.\Gamma\left(\frac{1}{\zeta_{1}}+1\right) \sum_{\kappa, h=0}^{\infty} \nabla_{\kappa, h}^{(\kappa, 1)}\right|_{1>-\zeta_{1}}, E\left(w^{2}\right)=\mu_{2}^{\prime}=\left.\Gamma\left(\frac{1}{\zeta_{1}}+1\right) \sum_{\kappa, h=0}^{\infty} \nabla_{\kappa, h}^{(\dot{k}, 2)}\right|_{2>-\zeta_{1}},
$$




$$
E\left(w^{3}\right)=\mu_{3}^{\prime}=\left.\Gamma\left(\frac{3}{\zeta_{1}}+1\right) \sum_{\kappa, h=0}^{\infty} \nabla_{\kappa, h}^{(\dot{\kappa}, 3)}\right|_{3>-\zeta_{1}} \text { and } E\left(w^{4}\right)=\mu_{4}^{\prime}=\left.\Gamma\left(\frac{4}{\zeta_{1}}+1\right) \sum_{\kappa, h=0}^{\infty} \nabla_{\kappa, h}^{(\dot{\kappa}, 4)}\right|_{4>-\zeta_{1}} .
$$

The last integration can be computed numerically for most parent distributions. The skewness and kurtosis measures can be calculated from the ordinary moments using well-known relationships. The moment generating function (MGF) $M_{W}(t)=E(\exp (t W))$ of $W$. Clearly, the first one can be derived from equation (9) as

where $r ! \nabla_{\kappa, h, r}^{(\dot{\kappa}, r)}=t^{r} \nabla_{\kappa, h}^{(\dot{\kappa}, r)} / r !$

$$
M_{W}(t)=\left.\Gamma\left(\frac{r}{\zeta_{1}}+1\right) \sum_{\kappa, h, r=0}^{\infty} \nabla_{\kappa, h, r}^{(\dot{\kappa}, r)}\right|_{r>-\zeta_{1}},
$$

\subsection{Incomplete moments}

The main applications of the first incomplete moment refer to the mean deviations and the Bonferroni and Lorenz curves. These curves are very useful in economics, reliability, demography, insurance and medicine. The $s^{t h}$ incomplete moment, say $I_{s}(t)$, of $W$ can be expressed from (9) as

$$
I_{s}(t)=\int_{-\infty}^{t} w^{s} f_{\delta, \zeta_{1}, \zeta_{2}}(w) d w=\left.\gamma\left(\frac{r}{\zeta_{1}}+1,\left(\frac{1}{t}\right)^{-\zeta_{1}}\right) \sum_{\kappa, h=0}^{\infty} \nabla_{\kappa, h}^{(\dot{\kappa}, r)}\right|_{s>-\zeta_{1}},
$$

setting $s=1,2,3,4$ in $I_{s}(t)$ we get

$$
\begin{aligned}
& I_{1}(t)=\left.\gamma\left(\frac{1}{\zeta_{1}}+1,\left(\frac{1}{t}\right)^{-\zeta_{1}}\right) \sum_{\kappa, h=0}^{\infty} \nabla_{\kappa, h}^{(\dot{\kappa}, 1)}\right|_{1>-\zeta_{1},} I_{2}(t)=\left.\gamma\left(\frac{2}{\zeta_{1}}+1,\left(\frac{1}{t}\right)^{-\zeta_{1}}\right) \sum_{\kappa, h=0}^{\infty} \nabla_{\kappa, h}^{(\dot{\kappa}, 2)}\right|_{2>-\zeta_{1}}, \\
& I_{3}(t)=\left.\gamma\left(\frac{3}{\zeta_{1}}+1,\left(\frac{1}{t}\right)^{-\zeta_{1}}\right) \sum_{\kappa, h=0}^{\infty} \nabla_{\kappa, h}^{(\dot{\kappa}, 3)}\right|_{2>-\zeta_{1}} \text { and } I_{4}(t)=\left.\gamma\left(\frac{4}{\zeta_{1}}+1,\left(\frac{1}{t}\right)^{-\zeta_{1}}\right) \sum_{\kappa, h=0}^{\infty} \nabla_{\kappa, h}^{(\dot{\kappa}, 4)}\right|_{4>-\zeta_{1}} .
\end{aligned}
$$

3.4 Probability weighted moments

The PWM method can generally be used for estimating parameters of a distribution whose inverse form cannot be expressed explicitly. The $(r, s)^{t h}$ PWM of $W$ following the MOGW distribution, say $\rho_{s, r}$, is formally defined by

$$
\rho_{s, r}=E\left\{w^{s} F_{\delta, \zeta_{1}, \zeta_{2}}(w)^{r}\right\}=\int_{-\infty}^{\infty} w^{s} F_{\delta, \zeta_{1}, \zeta_{2}}(w)^{r} f_{\delta, \zeta_{1}, \zeta_{2}}(w) d w .
$$

Using equations (5) and (6), we can write $f_{\delta, \zeta_{1}, \zeta_{2}}(w) F_{\delta, \zeta_{1}, \zeta_{2}}(w)^{r}=\sum_{\kappa=0}^{\infty} w_{\dot{\kappa}} \pi_{\dot{\kappa}}(w)$ where

$$
w_{\dot{\kappa}}=\frac{(-1)^{\kappa}}{\kappa !(\dot{\kappa})} \sum_{i, j=0}^{\infty}(-1)^{i+j}(i ! j !)^{-1} \delta^{i+1} \bar{\delta}^{j}(r)_{i}(-[i+2])_{j} \frac{\Gamma\left([i+j+1] \zeta_{2}\right)}{\Gamma\left([i+j+1] \zeta_{2}-\kappa\right)}
$$

Then, the $(r, s)^{t h}$ PWM of $W$ can be expressed as $\rho_{s, r}=\left.\Gamma\left(\frac{s}{\zeta_{1}}+1\right) \sum_{\kappa, h=0}^{\infty} \nabla_{\kappa, h}^{(\dot{\kappa}, s)}\right|_{s>-\zeta_{1}}$, where $\nabla_{\kappa, h}^{(\dot{\kappa}, s)}=w_{\dot{\kappa}} \nabla_{h}^{(\dot{\kappa}, s)}$.

3.5 Residual life and reversed residual life functions

The $m^{t h}$ moment of the residual life is $v_{m}(t)=E\left[(w-t)^{m} \mid w>t\right], m=1,2, \ldots$ The $m^{t h}$ moment of the residual life of $W$ is given by $v_{m}(t)=\frac{\int_{t}^{\infty}(w-t)^{m} d F_{\delta, \zeta_{1}, \zeta_{2}}(w)}{1-F_{\delta, \zeta_{1}, \zeta_{2}}(t)}$. Therefore,

$$
v_{m}(t)=\left.\Gamma\left(\frac{m}{\zeta_{1}}+1,\left(\frac{1}{t}\right)^{-\zeta_{1}}\right) \frac{1}{1-F_{\delta, \zeta_{1}, \zeta_{2}}(t)} \sum_{\kappa, h=0}^{\infty} \sum_{r=0}^{m} \nabla_{\kappa, h, r}^{(\dot{k}, m)}{ }^{\left(v_{m}\right)}\right|_{m>-\zeta_{1}},
$$

where $\nabla_{\kappa, h, r}^{(\dot{\kappa}, m)}{ }^{\left(\nu_{m}\right)}(1-t)^{-m}=\nabla_{\kappa, h}^{(\dot{\kappa}, m)}$. Another interesting function is the mean residual life (MRL) function or the life expectation at age $t$ defined by $v_{1}(t)=E[(w-t) \mid w>t]$, which represents the expected additional life length for a unit which is alive at age $t$. The MRL of $W$ can be obtained by setting $m=1$ in the last equation. The $m^{t h}$ moment of the reversed residual life is $V_{m}(t)=E\left[(t-w)^{m} \mid w \leq t\right]$ for $t>0$ and $m=1,2, \ldots$. Then, we obtain $V_{m}(t)=\frac{\int_{0}^{t}(t-w)^{m} d F_{\delta, \zeta_{1}, \zeta_{2}}(w)}{F_{\delta, \zeta_{1}, \zeta_{2}}(t)}$. Then, the $m^{t h}$ moment of the reversed residual life of $W$ becomes

$$
V_{m}(t)=\left.\gamma\left(\frac{m}{\zeta_{1}}+1,\left(\frac{1}{t}\right)^{-\zeta_{1}}\right) \frac{1}{F_{\delta, \zeta_{1}, \zeta_{2}}(t)} \sum_{\kappa, h=0}^{\infty} \sum_{r=0}^{m} \nabla_{\kappa, h, r}^{(\dot{\kappa}, m)}{ }^{\left(V_{m}\right)}\right|_{m>-\zeta_{1}}
$$

where $\left.\nabla_{\kappa, h, r}^{(\dot{\kappa}, m}\right)^{\left(V_{m}\right)}=(-1)^{r}\left(\begin{array}{c}m \\ r\end{array}\right) t^{m-r} \nabla_{\kappa, h}^{(\dot{\kappa}, m)}$. The mean inactivity time (MIT) or mean waiting time (MWT) also called the mean reversed residual life function is given by $M_{1}(t)=E[(t-w) \mid w \leq t]$, and it represents the waiting time 
elapsed since the failure of an item on condition that this failure had occurred in $(0, t)$. The MIT of the MOGW distribution of distributions can be obtained easily by setting $m=1$ in the above equation.

\subsection{Order statistics}

Suppose $w_{1}, w_{2}, \ldots, w_{n}$ is an observed random sample from any MOGW distribution. Let $w_{i: n}$ denote the $i^{\text {th }}$ order statistic. The PDF of $W_{i: n}$ can be expressed as

$$
f_{i: n}(w)=\frac{f_{\delta, \zeta_{1}, \zeta_{2}}(w)}{B(i, n-i+1)} \sum_{j=0}^{n-i}(-1)^{j}\left(\begin{array}{c}
n-i \\
j
\end{array}\right) F_{\delta, \zeta_{1}, \zeta_{2}}(w)^{j+i-1} .
$$

Following similar algebraic developments of Nadarajah et al. (2015), we can write the density function of $W_{i: n}$ as

$$
f_{i: n}(w)=\sum_{r, \kappa=0}^{\infty} b_{r, \kappa} \pi_{r+\dot{k}}(w)
$$

where $b_{r, \kappa}=\frac{n !(r+1)(i-1) ! t_{r+1}}{(r+\dot{\kappa})} \sum_{j=0}^{n-i} \quad \frac{(-1)^{j} \xi_{j+i-1, \kappa}}{(n-i-j) ! j !}, t_{\dot{\kappa}}$ is given in before and the quantities $\xi_{j+i-1, \kappa}$ can be determined with $\xi_{j+i-1,0}=w_{0}^{j+i-1}$ and recursively for $\kappa \geq 1, \xi_{j+i-1, \kappa}=\left(\kappa t_{0}\right)^{-1} \sum_{m=1}^{\kappa} t_{m}[m(j+i)-\kappa] \xi_{j+i-1, \kappa-m}$. Equation (11) is the main result of this section. It reveals that the PDF of the MOGW order statistics is a linear combination of exp W density functions. So, several mathematical quantities of the MOGW order statistics such as ordinary, incomplete and factorial moments, mean deviations and several others can be determined from those quantities of the $\exp \mathrm{W}$ distribution. For the MOGW model we have $E\left(w_{i: n}^{q}\right)=\left.\Gamma\left(\frac{q}{\zeta_{1}}+1\right) \sum_{r, \kappa, h=0}^{\infty} \nabla_{r, \kappa, h}^{(r+\dot{\kappa}, q)}\right|_{q>-\zeta_{1}}$ where $\nabla_{r, \kappa, h}^{(r+\dot{\kappa}, q)}=$ $b_{r, \kappa} \nabla_{h}^{(r+\dot{\kappa}, q)}$.

\section{Estimation}

Let $w_{1}, \ldots, w_{n}$ be a random sample from the MOGW distribution with parameters $\delta, \zeta_{2}$ and $\zeta_{1}$. Let $\Theta=\left(\delta, \zeta_{1}, \zeta_{2}\right)^{T}$ be the $3 \times 1$ parameter vector. For determining the MLE of $\Theta$, we have the log-likelihood function

$$
\ell=\ell(\Theta)=n \log \delta+n \log \zeta_{2}+n \log \zeta_{1}+\left(\zeta_{1}-1\right) \sum_{i=1}^{n} \log \left(w_{i}\right)-\zeta_{2} \sum_{i=1}^{n} w_{i}^{\zeta_{1}}-2 \sum_{i=1}^{n} \log s_{i},
$$

where $s_{i}=1-\dot{\delta} \exp \left(-\zeta_{2} w_{i}^{\zeta_{1}}\right)$. The components of the score vector are

and

$$
U_{\delta}=\frac{n}{\delta}-2 \sum_{i=1}^{n} \frac{z_{i}}{s_{i}}, U_{\zeta_{2}}=\frac{n}{\zeta_{2}}-\sum_{i=1}^{n} w_{i}^{\zeta_{1}}-2 \dot{\delta} \sum_{i=1}^{n} \frac{w_{i}^{\zeta_{1} z_{i}}}{s_{i}}
$$

$$
U_{\zeta_{1}}=\frac{n}{\zeta_{1}}+\sum_{i=1}^{n} \log \left(w_{i}\right)-\zeta_{2} \sum_{i=1}^{n} w_{i}^{\zeta_{1}} \log \left(w_{i}\right)-2 \dot{\delta} \zeta_{2} \sum_{i=1}^{n} w_{i}^{\zeta_{1}} s_{i}^{-1} \log \left(w_{i}\right) z_{i}
$$

Setting the nonlinear system of equations $U_{\delta}=U_{\zeta_{2}}=$ and $U_{\zeta_{1}}=0$ and solving them simultaneously yields the MLEs. To solve these equations, it is usually more convenient to use nonlinear optimization methods such as the quasi-Newton algorithm to numerically maximize $\ell$. For interval estimation of the parameters, we obtain the $3 \times 3$ observed information matrix $\mathbf{J}(\Theta)=\left\{\frac{\partial^{2} \ell}{\partial r \partial s}\right\} \quad$ (for $r, s=\delta, \zeta_{1}, \zeta_{2}$ ) whose elements can be computed numerically.

\section{Graphical assessment}

We perform a graphical simulation in order to assess of the finite sample behavior of the MLEs. The assessment was based on the following algorithm:

I-Using the quantile function, we generate 1000 samples of size $n$ from the MOGW distribution and compute the MLEs for the 1000 samples.

II -Compute the SEs of the MLEs for the 1000 samples.

III -Compute the biases and mean squared errors given for all parameters. We repeated these steps for $n=$ $50,100, \ldots, 250$, so computing biases, mean squared errors (MSEs) for $\delta, \zeta_{1}, \zeta_{2}$.

Figure 2 shows how the three biases vary with respect to $n$. Figure 3 shows how the three MSEs vary with respect to $n$. From Figure 2 and 3, the biases for each parameter are generally "negative" and decrease to zero as $n \rightarrow \infty$, the MSEs for each parameter decrease to zero as $n \rightarrow \infty$. 

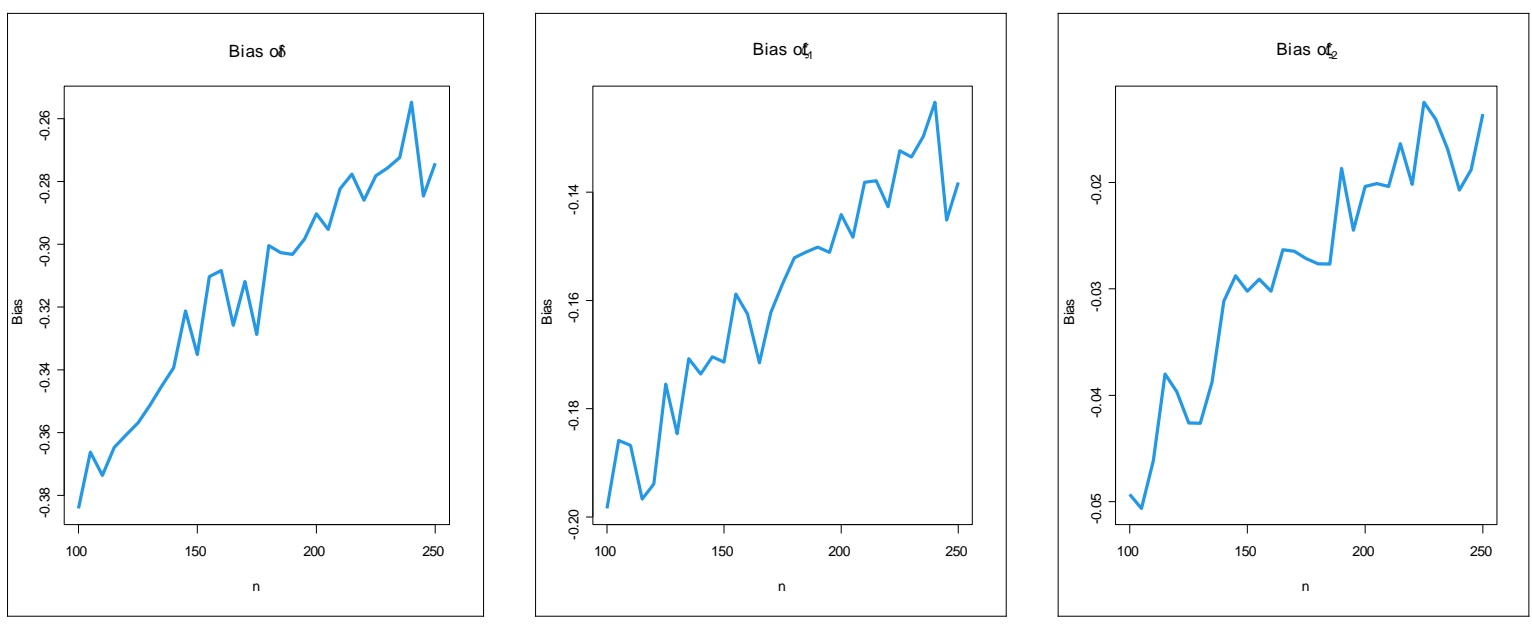

Figure 2: biases for all parameters.
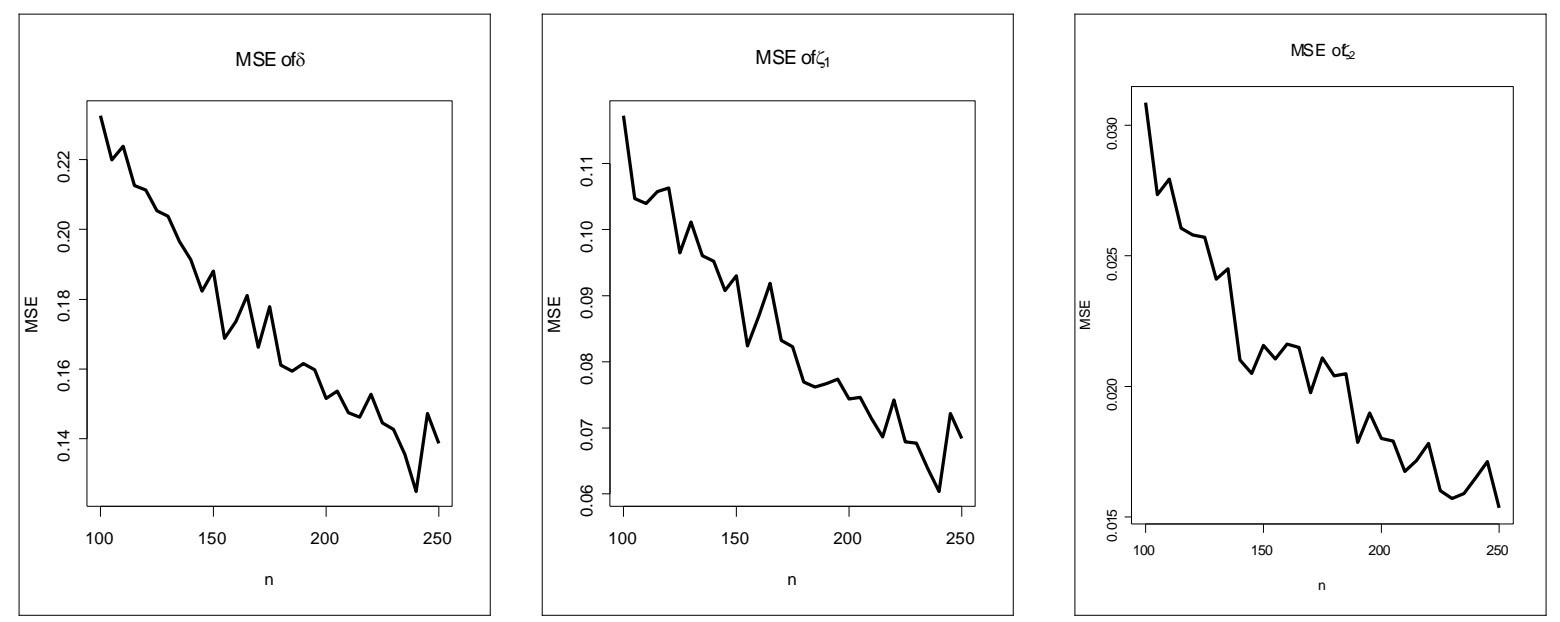

\section{Applications}

Figure 3: Mean squared errors for all parameters.

In this section, we provide four real applications to show empirically its potentiality. In order to compare the fits of the MOGW distribution with other competing distributions, we consider $C_{\text {(statistic) }}$ and the Anderson-Darling $A_{\text {(statistic) }}$. The MLEs and its standard errors (SEs) are given in Table 1, Table 3, Table 5 and Table 7. The values of $C_{\text {(statistic) }}$ and $A_{\text {(statistic) }}$ are listed in Table 2, Table 4, Table 6 and Table 8 . The total time in test (TTT), probability- probability (P-P) plots, Estimated PDF (EPHF), EHRF for data sets I, II, III and IV of the proposed models are displayed in Figure 4, Figure 5, Figure 6 and Figure 7. Some other extensions of the W distribution can also be used in this comparison, but are not limited to Alizadeh et al. (2017 and 2018), Yousof et al. (2016 a, b), Cordeiro et al. (2017a,b), Afify et al. (2016b), Brito et al. (2017), Yousof et al. (2017a-d), Korkmaz et al. (2018a), Yousof et al. (2018a,b), Aryal et al. (2017a,b) and Merovci et al. (2017 and 2020). Many symmetric and asymmetric real-life data can be found in Mansour et al. (2010a,d,e,f), Korkmaz et al. (2018b-d), Al-babtain et al. (2020a,b), Goual et al. (2019a,b), Yadav et al. (2020), Alizadeh et al. (2020a,b), Karamikabir et al. (2020) and Korkmaz et al. (2020).

6.1 Modeling failure times data 
The data consist of 84 observations. This data is recently analyzed by (Khalil et al. (2019) and Mansour et al. (2010b, c). In Table 1 and Table 2, we compared the fits of the MOGW distribution with the Odd Lindley exp W (OLEW), Burr-X exp W (BrXEW) (Khalil et al. (2019), MO- extended W (MOEW) (Ghitany et al. (2005)), Poisson ToppLeone W (PTLW), BetaW (BW) (Lee et al. (2007)), Kumaraswamy transmuted W (KwTW) (Afify et al. (2016a)), Transmuted-modified W (TMW) (Khan and King, (2013)), Gamma W (GamW) (Provost et al. (2011)), Kumaraswamy W (KwW) (Cordeiro et al. (2010)), W-Fréchet (W-Fr) (Afify et al. (2016c)), Modified-beta W (MBW) (Khan, (2015)) Mcdonald W (McW) (Cordeiro et al. (2014)), transmuted exp generalized W (TEGW) (Yousof et al. (2015)) models, whose PDFs (for $w>0$ ). The MOGW is the best model with $C_{(\text {statistic) }}=0.0679$ and $A_{\text {(statistic) }}=$ 0.5254 .

Table 1: MLEs and SEs for failure times data.

\begin{tabular}{|c|c|c|c|c|c|}
\hline \multirow{2}{*}{$\frac{\text { Distribution }}{\operatorname{MOGW}\left(\delta, \zeta_{1}, \zeta_{2}\right)}$} & \multicolumn{5}{|c|}{ Estimates } \\
\hline & $\begin{array}{r}27.592 \\
(57.29)\end{array}$ & $\begin{array}{l}1.264 \\
(1.361)\end{array}$ & $\begin{array}{l}1.0583 \\
(0.513)\end{array}$ & & \\
\hline $\operatorname{BrXEW}(\mathrm{a}, \mathrm{b}, \theta)$ & $\begin{array}{r}0.6368 \\
(0.36)\end{array}$ & $\begin{array}{l}4.262 \\
(1.76)\end{array}$ & $\begin{array}{l}0.536 \\
(0.10)\end{array}$ & & \\
\hline $\operatorname{OLEW}(\mathrm{a}, \mathrm{b}, \theta)$ & $\begin{array}{c}0.1594 \\
(0.371)\end{array}$ & $\begin{array}{l}0.732 \\
(1.78)\end{array}$ & $\begin{array}{l}0.765 \\
(0.041)\end{array}$ & & \\
\hline $\operatorname{PTLW}(\mathrm{a}, \mathrm{b}, \theta)$ & $\begin{array}{l}-5.782 \\
(1.395)\end{array}$ & $\begin{array}{l}4.229 \\
(1.167)\end{array}$ & $\begin{array}{l}0.658 \\
(0.039)\end{array}$ & & \\
\hline $\operatorname{GamW}(\mathrm{a}, \mathrm{b}, \theta)$ & $\begin{array}{l}2.377 \\
(0.38)\end{array}$ & $\begin{array}{l}0.8481 \\
(0.001)\end{array}$ & $\begin{array}{l}3.534 \\
(0.67)\end{array}$ & & \\
\hline $\operatorname{MOEW}(\mathrm{a}, \mathrm{b}, \theta)$ & $\begin{array}{l}488.90 \\
(189.36)\end{array}$ & $\begin{array}{l}0.283 \\
(0.01)\end{array}$ & $\begin{array}{l}1261.9 \\
(351.1)\end{array}$ & & \\
\hline $\mathrm{BW}(\alpha, \mathrm{a}, \mathrm{b}, \theta)$ & $\begin{array}{l}1.36 \\
(1.00)\end{array}$ & $\begin{array}{l}0.298 \\
(0.06)\end{array}$ & $\begin{array}{l}34.18 \\
(14.84)\end{array}$ & $\begin{array}{l}11.49 \\
(6.73)\end{array}$ & \\
\hline $\operatorname{TMW}(\alpha, \mathrm{a}, \mathrm{b}, \theta)$ & $\begin{array}{l}0.272 \\
(0: 01)\end{array}$ & $\begin{array}{l}1 \\
\left(5 \times 10^{-5}\right)\end{array}$ & $\begin{array}{l}4.6 \times 10^{-6} \\
\left(2 \times 10^{-4}\right)\end{array}$ & $\begin{array}{l}0.469 \\
(0.17)\end{array}$ & \\
\hline $\operatorname{WFr}(\alpha, \mathrm{a}, \mathrm{b}, \theta)$ & $\begin{array}{l}630.9 \\
(698)\end{array}$ & $\begin{array}{l}0.302 \\
(0.03)\end{array}$ & $\begin{array}{l}416.1 \\
(232.4)\end{array}$ & $\begin{array}{l}1.166 \\
(0.36)\end{array}$ & \\
\hline $\operatorname{KwW}(\alpha, \mathrm{a}, \mathrm{b}, \theta)$ & $\begin{array}{l}14.43 \\
(27.1)\end{array}$ & $\begin{array}{l}0.204 \\
(0.04)\end{array}$ & $\begin{array}{l}34.660 \\
(17.53)\end{array}$ & $\begin{array}{l}81.85 \\
(52.0)\end{array}$ & \\
\hline $\operatorname{TEGW}(\alpha, \lambda, \mathrm{a}, \mathrm{b}, \theta)$ & $\begin{array}{l}4.257 \\
(33.4)\end{array}$ & $\begin{array}{l}0.153 \\
(0.017)\end{array}$ & $\begin{array}{l}0.0978 \\
(0.609)\end{array}$ & $\begin{array}{l}5.231 \\
(9.79)\end{array}$ & $\begin{array}{l}1173.3 \\
(6.99)\end{array}$ \\
\hline $\operatorname{MBW}(\alpha, \lambda, a, b, \theta)$ & $\begin{array}{l}10.15 \\
(18.7)\end{array}$ & $\begin{array}{l}0.163 \\
(0.02)\end{array}$ & $\begin{array}{l}57.417 \\
(14.06)\end{array}$ & $\begin{array}{l}19.39 \\
(10.02)\end{array}$ & $\begin{array}{l}2.004 \\
(0.66)\end{array}$ \\
\hline $\operatorname{KwTW}(\alpha, \lambda, \mathrm{a}, \mathrm{b}, \theta)$ & $\begin{array}{l}27.79 \\
(33.4)\end{array}$ & $\begin{array}{l}0.178 \\
(0.02)\end{array}$ & $\begin{array}{l}0.445 \\
(0.609)\end{array}$ & $\begin{array}{l}29.525 \\
(9.792)\end{array}$ & $\begin{array}{l}168.06 \\
(129.2)\end{array}$ \\
\hline $\operatorname{McW}(\alpha, \lambda, a, b, \theta)$ & $\begin{array}{l}1.940 \\
(1.01)\end{array}$ & $\begin{array}{l}0.306 \\
(0.045)\end{array}$ & $\begin{array}{l}17.686 \\
(6.222)\end{array}$ & $\begin{array}{l}33.639 \\
(19.99)\end{array}$ & $\begin{array}{l}16.721 \\
(9.722)\end{array}$ \\
\hline
\end{tabular}

Table 2: $C_{\text {(statistic) }}$ and $A_{\text {(statistic) }}$ for failure times data.

\begin{tabular}{cll}
\hline Distribution & $C_{\text {(statistic) }}$ & $A_{\text {(statistic) }}$ \\
\hline MOGW & 0.0679 & 0.5254 \\
GamW & 0.2553 & 1.9489 \\
OLEW & 0.0723 & 0.6086 \\
BW & 0.4652 & 3.2197 \\
BrXEW & 0.0744 & 0.6420 \\
MBW & 0.4717 & 3.2656 \\
PTLW & 0.1402 & 1.1939 \\
TMW & 0.8065 & 11.204 \\
MOEW & 0.3995 & 4.4477
\end{tabular}




\begin{tabular}{ccc} 
KwW & 0.1852 & 1.5059 \\
KwTW & 0.1640 & 1.3632 \\
McW & 0.1986 & 1.5906 \\
TEGW & 1.0079 & 6.2332 \\
WFr & 0.2537 & 1.9574 \\
\hline
\end{tabular}
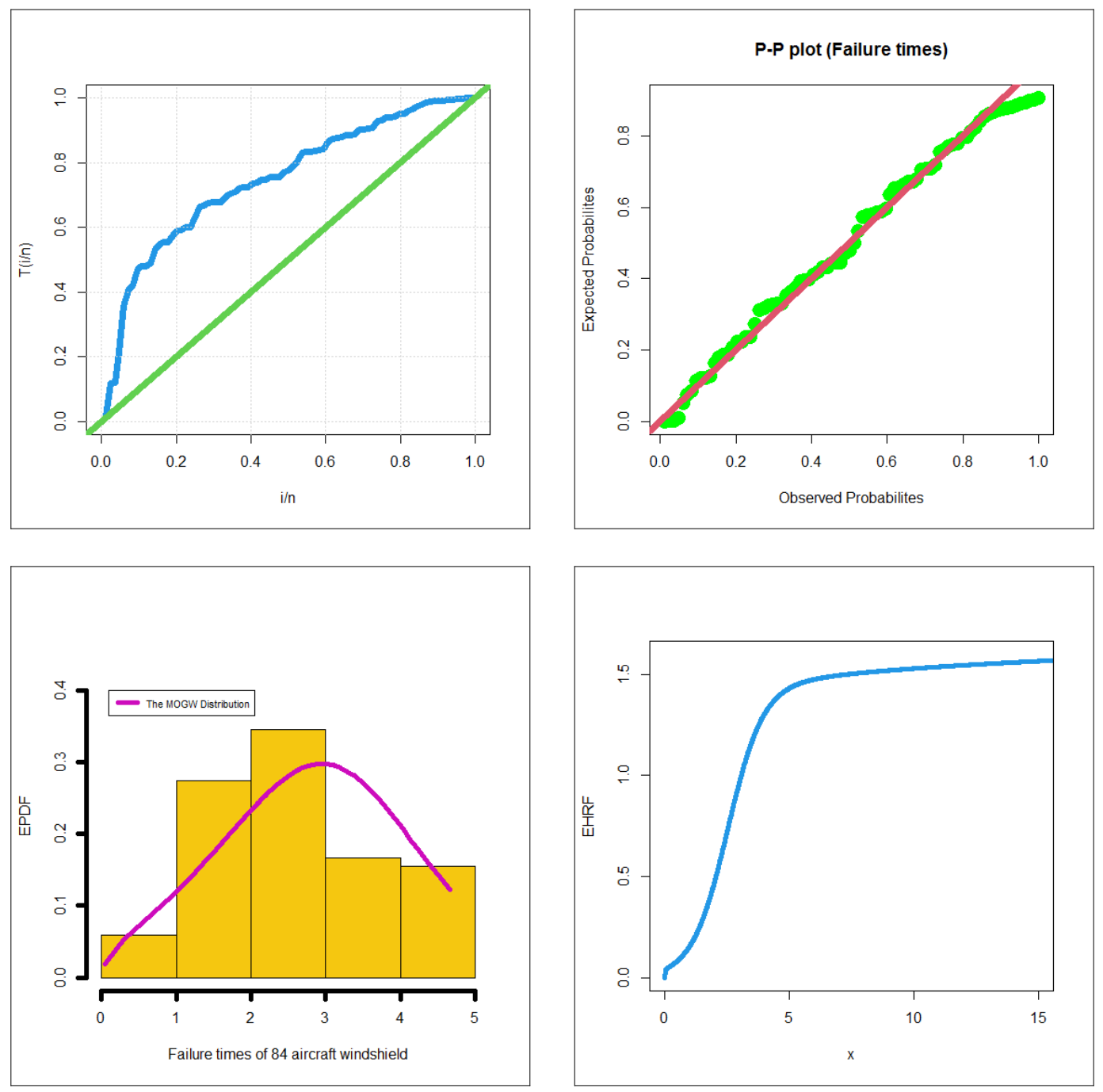

Figure 4: TTT plot, P-P plot, EPHF, EHRF for failure times data.

6.2 Modeling cancer data

This data set represents the remission times (in months) of a random sample of 128 bladder cancer patients as reported in Lee and Wang (2003). This data is recently analyzed by (Khalil et al. (2019) and Mansour et al. (2010b, c).We compare the fits of the MOGW distribution with other competitive models, namely: The TMW, MBW, transmuted additive W distribution (TAW) (Elbatal and Aryal, (2013)), exponentiated transmuted generalized Rayleigh (ETGR) (Afify et al. (2015)), and the Weibull distributions with corresponding densities (for $w>0$ ). Based on the figures in Table 4 we conclude that the proposed MOGW lifetime model is much better than the W, TMW, MBW, TAW, ETGR models with $C_{\text {(statistic) }}=0.0672$ and $A_{\text {(statistic) }}=0.4214$. 


\begin{tabular}{cccccc}
\hline Distribution & \multicolumn{5}{c}{ Estimates } \\
\hline $\mathrm{W}(\alpha, \beta)$ & 9.559 & 1.048 & & & \\
& $(0.85)$ & $(0.068)$ & & & \\
$\operatorname{MOGW}\left(\delta, \zeta_{1}, \zeta_{2}\right)$ & 0.6684 & 0.169 & 0.822 & & \\
& $(0.126)$ & $(0.028)$ & $(0.003)$ & & \\
$\operatorname{ETG}-\mathrm{R}(\alpha, \mathrm{a}, \mathrm{b}, \theta)$ & 7.3762 & 0.0473 & 0.0494 & 0.118 & \\
& $(5.39)$ & $\left(4 \times 10^{-3}\right)$ & $(0.036)$ & $(0.26)$ & \\
$\operatorname{TMW}(\alpha, \mathrm{a}, \mathrm{b}, \theta)$ & 0.121 & 0.8955 & 0.0002 & 0.251 & \\
& $(0.024)$ & $(0.626)$ & $(0.011)$ & $(0.407)$ & \\
$\operatorname{TAW}(\alpha, \beta, \mathrm{a}, \mathrm{b}, \theta)$ & 0.1139 & 0.972 & $3 \times 10^{-5}$ & 1.0065 & -0.16 \\
& $(0.032)$ & $(0.125)$ & $\left(6 \times 10^{-3}\right)$ & $(0.035)$ & $(0.28)$ \\
$\operatorname{MBW}(\alpha, \beta, \mathrm{a}, \mathrm{b}, \theta)$ & 0.1502 & 0.163 & 57.4167 & 19.39 & 2.004 \\
& $(22.44)$ & $(0.044)$ & $(37.32)$ & $(13.5)$ & $(0.79)$ \\
\hline
\end{tabular}

Table 4: $C_{\text {(statistic) }}$ and $A_{\text {(statistic) }}$ for remission data.

\begin{tabular}{cll}
\hline Distribution & $C_{\text {(statistic) }}$ & $A_{\text {(statistic) }}$ \\
\hline MOGW & 0.0672 & 0.4214 \\
ETG-R & 0.3979 & 2.3608 \\
W & 0.1055 & 0.6628 \\
TAW & 0.1129 & 0.7033 \\
TMW & 0.1251 & 0.7603 \\
MBW & 0.1068 & 0.7207 \\
\hline
\end{tabular}
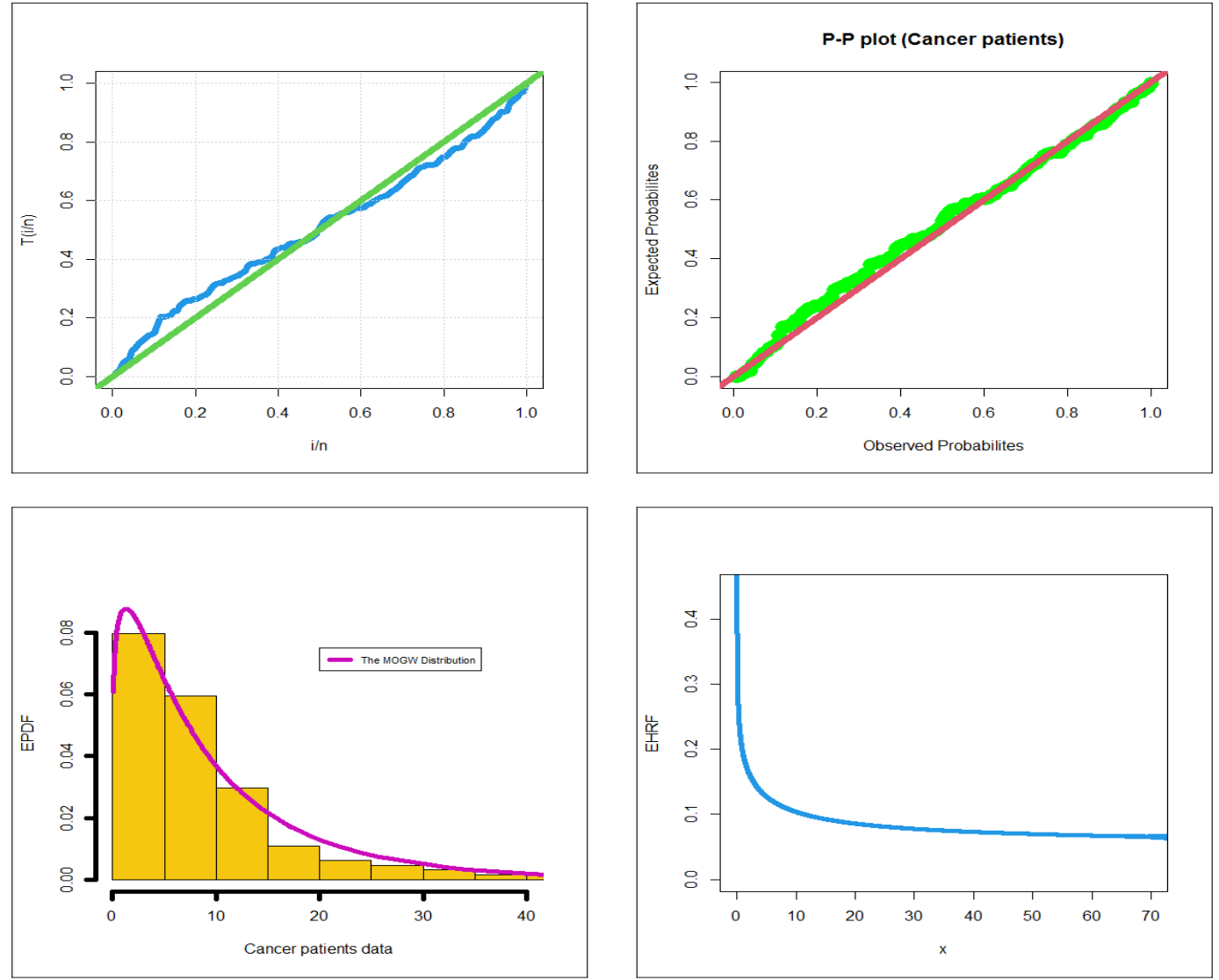

Figure 5: TTT plot, P-P plot, EPHF, EHRF for remission data set. 
6.3 Modeling survival times

The second real data set corresponds to the survival times (in days) of 72 guinea pigs infected with virulent tubercle bacilli (see Bjerkedal (1960)). This data is recently analyzed by (Khalil et al. (2019) and Mansour et al. (2010b, c). We shall compare the fits of the MOGW distribution with those of other competitive models, namely: Odd Lindley exponentiated W (OLEW), the Odd WW (OWW) (Bourguignon et al. (2014)), the gamma exponentiated-exponential (GaE-E) (Ristic and Balakrishnan (2012)). Based on the figures in Table 6 we conclude that the proposed MOGW model is much better than all other models with $C_{\text {(statistic) }}=0.0961$ and $A_{\text {(statistic) }}=0.6897$.
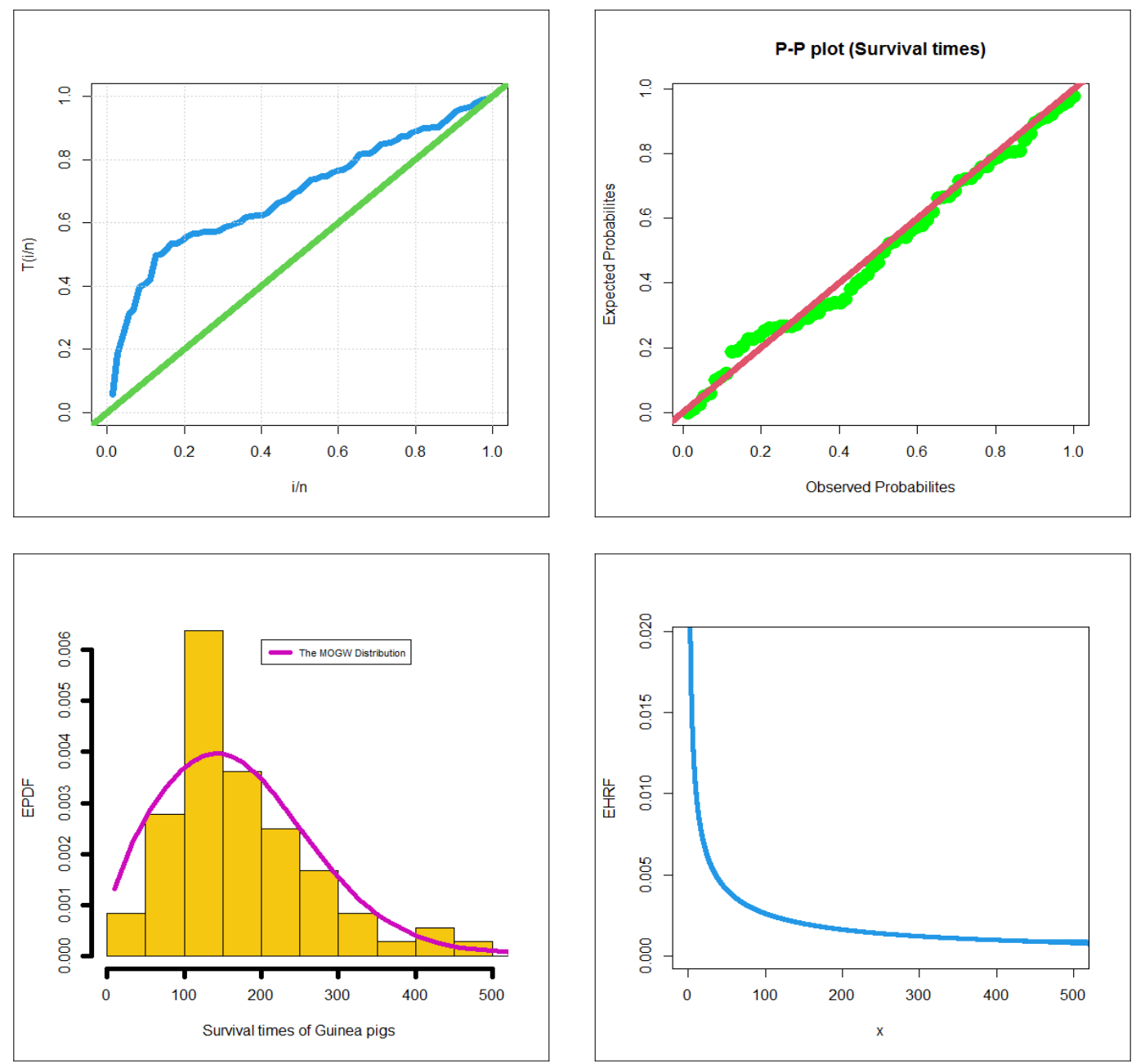

Figure 6: TTT plot, P-P plot, EPHF, EHRF for survival data.

Table 5: MLEs and SEs for survival data.

\begin{tabular}{clll}
\hline Distribution & \multicolumn{3}{c}{ Estimates } \\
\hline MOGW $\left(\delta, \zeta_{1}, \zeta_{2}\right)$ & 0.0622 & 0.003 & 0.5686 \\
& $(0.022)$ & $(0.001)$ & $(0.002)$ \\
OWW $(\mathrm{a}, \mathrm{b}, \theta)$ & 11.158 & 0.088 & 0.457 \\
& $(4.545)$ & $(0.036)$ & $(0.08)$ \\
GaE-E $(\mathrm{a}, \mathrm{b}, \theta)$ & 2.114 & 2.601 & 0.008 \\
& $(1.329)$ & $(0.560)$ & $(0.01)$ \\
OLEW $(\mathrm{a}, \mathrm{b}, \theta)$ & 0.0018 & 0.0716 & 0.2813 \\
& $(0.0004)$ & $(0.025)$ & $(0.009)$ \\
\hline
\end{tabular}


Table 6: $C_{\text {(statistic) }}$ and $A_{\text {(statistic) }}$ for survival data.

\begin{tabular}{cll}
\hline Distribution & $C_{\text {(statistic) }}$ & $A_{\text {(statistic) }}$ \\
\hline MOGW & 0.096 & 0.689 \\
GaE-E & 0.315 & 1.721 \\
OLEW & 0.252 & 1.475 \\
OWW & 0.449 & 2.476 \\
\hline
\end{tabular}

6.4 Modeling strengths data

This data consists of 63 observations of the strengths of $1.5 \mathrm{~cm}$ glass fibers. This data is recently analyzed by (Khalil et al. (2019) and Mansour et al. (2010b, c). We shall compare the fits of the MOGW with the OLEW, EW, TW and OLLW. Based on the Table 8 we conclude that the proposed MOGW model is the best model with $C_{\text {(statistic) }}=$ 0.1630 and $A_{\text {(statistic) }}=0.0925$.
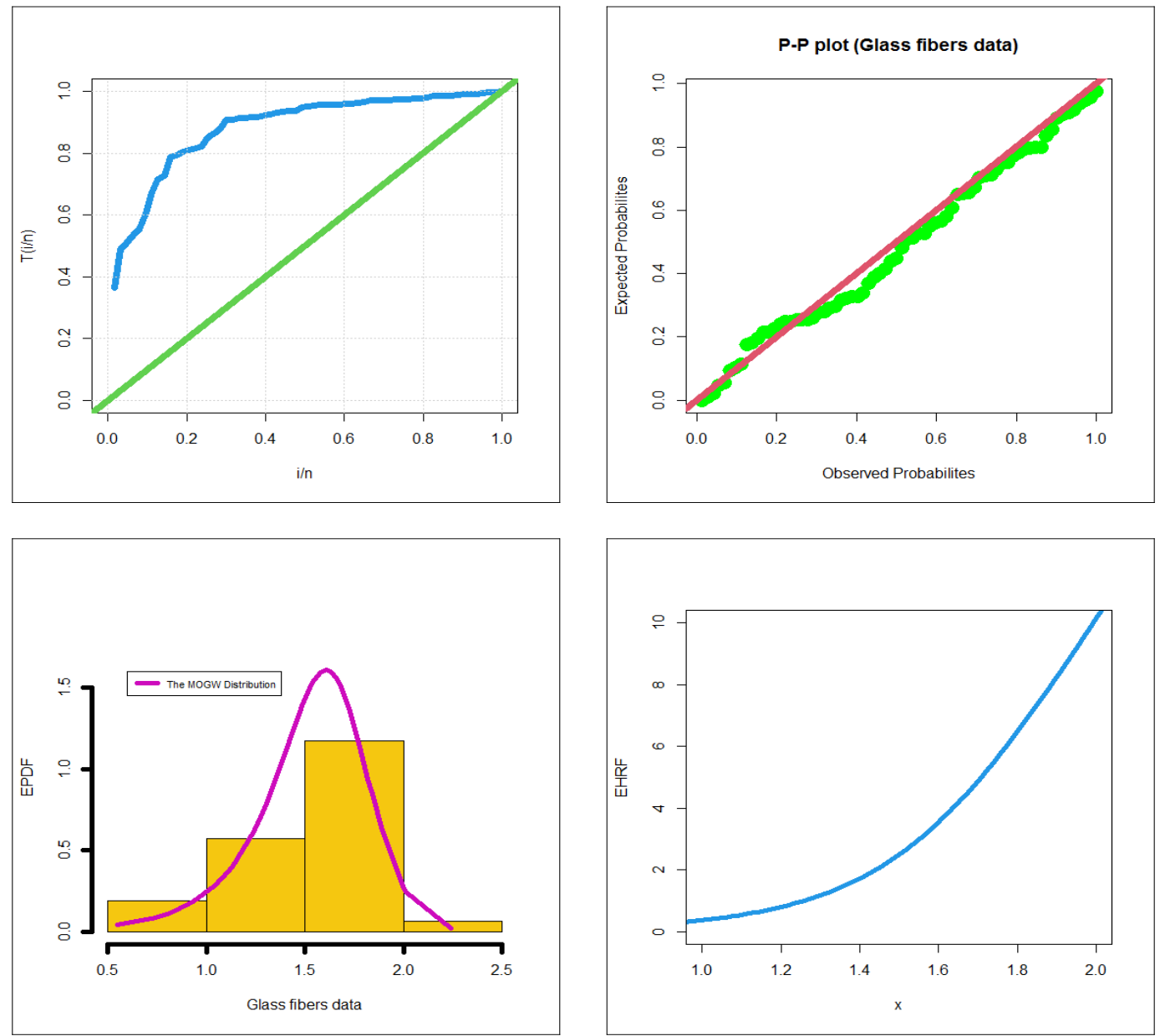

Figure 7: TTT plot, P-P plot, EPHF, EHRF for strengths data. 
Table 7: MLEs and SEs for strengths data.

\begin{tabular}{clcc}
\hline Distribution & \multicolumn{3}{c}{ Estimates } \\
\hline MOGW $\left(\delta, \zeta_{1}, \zeta_{2}\right)$ & 2.950 & 0.212 & 4.4548 \\
& $(1.016)$ & $(0.034)$ & $(0.003)$ \\
EW $(\mathrm{a}, \mathrm{b}, \theta)$ & 0.671 & 7.285 & 1.7180 \\
& $(0.25)$ & $(1.71)$ & $(0.094)$ \\
OLEW $(\mathrm{a}, \mathrm{b}, \theta)$ & 0.508 & 2.534 & 1.7122 \\
& $(0.39)$ & $(1.83)$ & $(0.096)$ \\
OLLW $(\mathrm{a}, \mathrm{b}, \theta)$ & 0.944 & 6.026 & 0.6159 \\
& $(0.27)$ & $(1.35)$ & $(0.016)$ \\
TW $(\mathrm{a}, \mathrm{b}, \theta)$ & -0.501 & 5.149 & 0.6465 \\
& $(0.27)$ & $(0.67)$ & $(0.024)$ \\
& & & \\
Table 8: $C_{(\text {statistic })}$ and $A_{\text {(statistic) }}$ for strengths data. \\
\hline Distribution & $C_{(\text {statistic) }}$ & $A_{(\text {statistic) }}$ \\
\hline MOGW & 0.1630 & 0.0925 \\
OLLW & 1.2364 & 0.2194 \\
OLEW & 0.2711 & 1.49645 \\
TW & 1.0358 & 0.1691 \\
EW & 0.636 & 3.4840 \\
\hline
\end{tabular}

\section{Concluding remarks}

This article presented a new three-parameter life parametric model called the Marshall-Olkin generalized Weibull (MOGW) model. Some of its relevant structural properties are derived and analyzed. The new density is expressed as a linear mixture of the exponentiated Weibull density. The density of the MOGW distribution exhibits various important symmetric and asymmetric shapes with different useful kurtosis. The HRF of the MOGW model can be "constant", "upside down-constant (reversed U-HRF-constant)", "increasing then constant", "monotonically increasing", "J-HRF" and "monotonically decreasing". The maximum likelihood method is employed to estimate the unknown model parameters. A graphical simulation is performed to assess the performance of the maximum likelihood estimation biases, mean squared errors. It is noted that the three biases are generally "negative" and decrease to zero as $n \rightarrow \infty$, the mean squared errors for each parameter decrease to zero as $n \rightarrow \infty$. We checked and proved empirically the importance, applicability and flexibility of the new Weibull model in modeling various symmetric and asymmetric types of data. The new distribution has a high ability to model different symmetric and asymmetric types of data.

\section{References}

1. Afify, A. Z., Cordeiro, G. M., Yousof, H. M. Alzaatreh, A., and Nofal, Z. M. (2016a). The Kumaraswamy transmuted$\mathrm{G}$ family of distributions: properties and applications, 14, 245-270.

2. Afify, A.Z., Cordeiro, G. M., Yousof, H. M., Saboor, A. and Ortega, E. M. M. (2016b). The Marshall-Olkin additive Weibull distribution with variable shapes for the hazard rate. Hacettepe Journal of Mathematics and Statistics, 47, 365 381.

3. Afify, A. Z., Nofal, Z. M. and Ebraheim, A. N. (2015). Exponentiated transmuted generalized Rayleigh distribution: A new four parameter Rayleigh distribution. Pak.j.stat.oper.res, 11 (1), 115-134.

4. Afify, A. Z., Yousof, H. M., Cordeiro, G. M., Ortega, E. M. M. and Nofal, Z. M. (2016c). The Weibull Fréchet distribution and its applications. Journal of Applied Statistics, 43 (14), 2608-2626.

5. Al-Babtain, A. A., Elbatal, I. and Yousof, H. M. (2020a). A new three parameter Fréchet model with mathematical properties and applications. Journal of Taibah University for Science, 14(1), 265-278.

6. Al-babtain, A. A., Elbatal, I. and Yousof, H. M. (2020b). A new flexible three-parameter model: properties, clayton copula, and modeling real data. Symmetry, 12(3), 440.

7. Alizadeh, M., Ghosh, I., Yousof, H. M., Rasekhi, M. and Hamedani G. G. (2017). The generalized odd generalized exponential family of distributions: properties, characterizations and applications, J. Data Sci. 15, 443-466.

8. Alizadeh, M., Jamal, F., Yousof, H. M., Khanahmadi, M. and Hamedani, G. G. (2020a). Flexible Weibull generated family of distributions: characterizations, mathematical properties and applications. University Politehnica of Bucharest Scientific Bulletin-series A - Applied Mathematics and Physics, 82(1), 145-150. 
9. Alizadeh, M., Rasekhi, M., Yousof, H. M. and Hamedani G. G. (2018). The transmuted Weibull G family of distributions. Hacettepe Journal of Mathematics and Statistics, 47(6), 1-20.

10. Alizadeh, M., Yousof, H. M., Jahanshahi, S. M. A., Najibi, S. M. and Hamedani, G. G. (2020b). The transmuted odd loglogistic-G family of distributions. Journal of Statistics and Management Systems, 1-27.

11. Arya, G. R., Ortega, E. M., Hamedani, G. G. and Yousof, H. M. (2017a). The ToppLeone Generated Weibull distribution: regression model, characterizations and applications, International Journal of Statistics and Probability, 6, 126-141.

12. Aryal, G. R. and Yousof, H. M. (2017b). The exponentiated generalized-G Poisson family of distributions. Economic Quality Control, 32(1), 1-17.

13. Bjerkedal, T. (1960). Acquisition of resistance in guinea pigs infected with different doses of virulent tubercle bacilli. American Journal of Hygiene, 72, 130--148.

14. Bourguignon, M., Silva, R.B. and Cordeiro, G.M. (2014). The Weibull-G family of probability distributions, Journal of Data Science 12, 53--68.

15. Brito, E., Cordeiro, G. M., Yousof, H. M., Alizadeh, M. and Silva, G. O. (2017). Topp-Leone Odd Log-Logistic Family of Distributions, Journal of Statistical Computation and Simulation, 87(15), 3040--3058.

16. Cordeiro, G. M., Afify, A. Z., Yousof, H. M., Pescim, R. R. and Aryal, G. R. (2017a). The exponentiated Weibull-H family of distributions: Theory and Applications. Mediterranean Journal of Mathematics, 14, 1-22.

17. Cordeiro, G.M., Afify, A. Z., Yousof, H. M., Cakmakyapan, S. and Ozel, G. (2018). The Lindley Weibull distribution: properties and applications, Anais da Academia Brasileira de Ciências, forthcoming.

18. Cordeiro, G. M., Hashimoto, E. M., Edwin, E. M. M. Ortega. (2014). The McDonald Weibull model. Statistics: A Journal of Theoretical and Applied Statistics, 48, 256-278.

19. Cordeiro, G. M., Ortega, E. M. and Nadarajah, S. (2010). The Kumaraswamy Weibull distribution with application to failure data. Journal of the Franklin Institute, 347, 1399--1429.

20. Cordeiro, G. M., Yousof, H. M., Ramires, T. G. and Ortega, E. M. M. (2017b). The Burr XII system of densities: properties, regression model and applications. Journal of Statistical Computation and Simulation, 88(3), 432-456.

21. Elbatal, I. and Aryal, G. (2013). On the transmuted additive Weibull distribution. Austrian Journal of Statistics, 42(2), 117-132.

22. Goual, H., Yousof, H. M. and Ali, M. M. (2019a). Validation of the odd Lindley exponentiated exponential by a modified goodness of fit test with applications to censored and complete data. Pak. J. Stat. Oper. Res. 15(3), 745-771.

23. Goual, H. and Yousof, H. M. (2019b). Validation of Burr XII inverse Rayleigh model via a modified chi-squared goodness-of-fit test. Journal of Applied Statistics, 47(1), 1-32.

24. Karamikabir, H., Afshari, M., Yousof, H. M., Alizadeh, M. and Hamedani, G. (2020). The Weibull Topp-Leone Generated Family of Distributions: Statistical Properties and Applications. Journal of The Iranian Statistical Society, 19(1), 121-161.

25. Khalil, M. G., Hamedani G. G. and Yousof, H. M. (2019). The Burr X exponentiated Weibull model: characterizations, mathematical properties and applications to failure and survival times data. Pak. J. Stat. Oper. Res., XV(1), 141-160.

26. Khan, M. N. (2015). The modified beta Weibull distribution. Hacettepe Journal of Mathematics and Statistics, 44, 15531568.

27. Khan, M. S. and King, R. (2013). Transmuted modified Weibull distribution: a generalization of the modified Weibull probability distribution. European Journal of Pure and Applied Mathematics, 6, 66-88.

28. Korkmaz, M. C., Alizadeh, M., Yousof, H. M. and Butt, N. S. (2018a). The generalized odd Weibull generated family of distributions: statistical properties and applications. Pak. J. Stat. Oper. Res., 14(3), 541-556.

29. Korkmaz, M. Ç., Altun, E., Yousof, H. M. and Hamedani, G. G. (2020). The Hjorth's IDB Generator of Distributions: Properties, Characterizations, Regression Modeling and Applications. Journal of Statistical Theory and Applications, 19(1), 59-74.

30. Korkmaz, M. Ç., Yousof, H. M. and Hamedani, G. G. (2018b). The exponential Lindley odd log-logistic-G family: properties, characterizations and applications. Journal of Statistical Theory and Applications, 17(3), 554-571.

31. Korkmaz, M. C., Yousof, H. M., Hamedani G. G. and Ali, M. M. (2018c). The Marshall-Olkin generalized G Poisson family of distributions, Pakistan Journal of Statistics, 34(3), 251-267.

32. Korkmaz, M. C., Yousof, H. M., Rasekhi, M. and Hamedani, G. G. (2018d). The Odd Lindley Burr XII Model: Bayesian Analysis, Classical Inference and Characterizations. Journal of Data Science, 16(2), 327-353.

33. Lee, E. T. and Wang, J. (2003). Statistical methods for survival data analysis (Vol. 476). John Wiley \& Sons.

34. Lee, C., Famoye, F. and Olumolade, O. (2007). Beta Weibull distribution: some properties and applications to censored data. Journal of Modern Applied Statistical Methods, 6, 17.

35. Merovci, F., Alizadeh, M., Yousof, H. M. and Hamedani G. G. (2017). The exponentiated transmuted-G family of distributions: theory and applications, Communications in Statistics-Theory and Methods, 46(21), 10800-10822.

36. Merovci, F., Yousof, H. and Hamedani, G. G. (2020). The Poisson Topp Leone Generator of Distributions for Lifetime Data: Theory, Characterizations and Applications. Pakistan Journal of Statistics and Operation Research, 16(2), 343-355. 
37. Mansour, M. M., Ibrahim, M., Aidi, K., Shafique Butt, N., Ali, M. M., Yousof, H. M. and Hamed, M. S. (2020a). A New Log-Logistic Lifetime Model with Mathematical Properties, Copula, Modified Goodness-of-Fit test for Validation and Real Data Modeling. Mathematics, 8(9), 1508.

38. Mansour, M. M., Butt, N. S., Ansari, S. I., Yousof, H. M., Ali, M. M., Ibrahim, M. (2020b). A new exponentiated Weibull distribution's extension: copula, mathematical properties and applications. Contributions to Mathematics, 1 (2020) 5766. DOI: $10.47443 / \mathrm{cm} .2020 .0018$

39. Mansour, M., Korkmaz, M. C, Ali, M. M., Yousof, H. M., Ansari, S. I. and Ibrahim, M. (2020c). A Generalization of the exponentiated Weibull model with properties, copula and application. Eurasian Bulletin of Mathematics, 3(2), 84-102.

40. Mansour, M., Rasekhi, M., Ibrahim, M., Aidi, K., Yousof, H. M. and Elrazik, E. A. (2020d). A New Parametric Life Distribution with Modified Bagdonavičius-Nikulin Goodness-of-Fit Test for Censored Validation, Properties, Applications, and Different Estimation Methods. Entropy, 22(5), 592.

41. Mansour, M., Yousof, H. M., Shehata, W. A. and Ibrahim, M. (2020e). A new two parameter Burr XII distribution: properties, copula, different estimation methods and modeling acute bone cancer data. Journal of Nonlinear Science and Applications, 13(5), 223-238.

42. Mansour, M. M., Butt, N. S., Yousof, H., Ansari, S. I. and Ibrahim, M. (2020f). A Generalization of Reciprocal Exponential Model: Clayton Copula, Statistical Properties and Modeling Skewed and Symmetric Real Data Sets. Pakistan Journal of Statistics and Operation Research, 373-386.

43. Nadarajah, S., Cordeiro, G. M. and Ortega, E. M. M. (2015). The exponentiated Weibull distribution: A survey, Statistical Papers, 54, 839-877.

44. Provost, S.B. Saboor, A. and Ahmad, M. (2011). The gamma Weibull distribution, Pak. Journal Stat., 27, $111--131$.

45. Ristic, M.M. and Balakrishnan, N. (2012). The gamma-exponentiated exponential distribution, Journal of Statistical Computation and Simulation, 82, 1191-1206.

46. Weibull, W. (1951). A statistical distribution function of wide applicability. J. Appl. Mech.-Trans, 18(3), 293-297.

47. Yadav, A. S., Goual, H., Alotaibi, R. M., Ali, M. M. and Yousof, H. M. (2020). Validation of the Topp-Leone-Lomax model via a modified Nikulin-Rao-Robson goodness-of-fit test with different methods of estimation. Symmetry, 12(1), 57.

48. Yousof, H. M., Afify, A. Z., Alizadeh, M., Nadarajah, S., Aryal, G. R. and Hamedani, G. G. (2018a). The Marshall-Olkin generalized-G family of distributions with Applications, STATISTICA, 78(3), 273- 295.

49. Yousof, H. M., Afify, A. Z., Cordeiro, G. M., Alzaatreh, A., and Ahsanullah, M. (2017a). A new four-parameter Weibull model for lifetime data. Journal of Statistical Theory and Applications, 16(4), 448 - 466.

50. Yousof, H. M., Afify, A. Z., Hamedani, G. G. and Aryal, G. (2017b). The Burr X generator of distributions for lifetime data. Journal of Statistical Theory and Applications, 16, 288--305.

51. Yousof, H. M., Alizadeh, M., Jahanshahi, S. M. A., Ramires, T. G., Ghosh, I. and Hamedani G. G. (2017c). The transmuted Topp-Leone G family of distributions: theory, characterizations and applications, Journal of Data Science. $15,723-740$

52. Yousof, H. M., Majumder, M., Jahanshahi, S. M. A., Ali, M. M. and Hamedani G. G. (2018b). A new Weibull class of distributions: theory, characterizations and applications, Journal of Statistical Research of Iran, 15, 45-83.

53. Yousof, H. M., Rasekhi, M., Afify, A. Z., Alizadeh, M., Ghosh, I. and Hamedani G. G. (2017d). The beta Weibull-G family of distributions: theory, characterizations and applications, Pakistan Journal of Statistics, 33, 95-116. 